\title{
Severe Hepatic Sinusoidal Obstruction Syndrome during the Induction Chemotherapy of Burkitt's Lymphoma
}

\author{
Line Couitchere1, Yao Nicaise Atiméré ${ }^{2 *}$, Daouda Koné2, Delphine Lagou ${ }^{3}$ \\ ${ }^{1}$ Paediatric Ward of University and Teaching Hospital of Treichville, Abidjan, Côte d'Ivoire \\ ${ }^{2}$ Hematology Ward of University and Teaching Hospital of Treichville, Abidjan, Côte d'Ivoire \\ ${ }^{3}$ Nephrology Ward of University and Teaching Hospital of Yopougon, Abidjan, Côte d'Ivoire \\ Email: *atimerenicaise@yahoo.fr
}

How to cite this paper: Couitchere, L., Atiméré, Y.N., Koné, D. and Lagou, D. (2018) Severe Hepatic Sinusoidal Obstruction Syndrome during the Induction Chemotherapy of Burkitt's Lymphoma. Open Journal of Blood Diseases, 8, 10-16. https://doi.org/10.4236/ojbd.2018.81002

Received: December 22, 2017

Accepted: March 6, 2018

Published: March 9, 2018

Copyright (c) 2018 by authors and Scientific Research Publishing Inc. This work is licensed under the Creative Commons Attribution International License (CC BY 4.0).

http://creativecommons.org/licenses/by/4.0/

\begin{abstract}
The Hepatic sinusoidal obstruction syndrome (HSOS), also known as veno-occlusive disease (VOD), is a well-known complication of haematopoietic stem cell transplantation, of the treatment of Wilms tumor and rhabdomyosarcoma and maintenance therapy of acute lymphoblastic leukemias. Its occurrence is rare in other cancers of the child. We report the observation of a 7-year-old girl with Burkitt's lymphoma who developed a severe HSOS during her second induction treatment with dexamethasone, cisplatin, cytosine arabinoside. The evolution was fatal. This observation shows that the diagnosis of HSOS should not be excluded in the absence of the risk factors usually described.
\end{abstract}

\section{Keywords}

Lymphoma, Treatment, Veno-Occlusive Disease, Multi Organ Failure

\section{Introduction}

The serous hepatosis or Hepatic sinusoidal obstruction syndrome (HSOS) is due to an occlusion of the terminal hepatic venules and hepatic sinusoids. It is characterized clinically by painful hepatomegaly, hyper bilirubinemia and/or jaundice and rapid weight gain in relation to hydro-sodium retention. This frequent complication of transplantation of hematopoietic stem cells is also described during the chemotherapy of nephroblastoma and rhabdomyosarcoma. This syndrome is rare in conventional chemotherapy and in other childhood cancers [1] [2] [3]. We report the observation of a 7-year-old girl who developed 
a severe VOD during the treatment of Burkitt's lymphoma.

\section{Case Report}

A 7-year-old girl is referred for the management of a left genogenic tumor that has been evolving for four months. The clinical examination at admission noted a voluminous unilateral left maxillary facial tumor ulcerated $10 \mathrm{~cm}$ long and a polylobed hypogastric mass measuring $5 \mathrm{~cm}$ long. The CT of the facial mass (Figure 1(a) and Figure 1(b)) had emphasized the presence of a voluminous tumor of the left hemiface with extension to the orbit, maxillary sinus and a lysis of the mandible. The abdominal ultrasound had revealed the presence of multiple coelio-mesenteric and pelvic adenopathies related to a secondary localization. The biospy histological examination of the maxillofacial tumor biopsy (Figure 2) gave a compatible appearance with Burkitt's lymphoma. The staging (pulmonary radiography, myelogram and CSF fine cytology) was normal. The patient was classified as stage III in the classification of Saint Jude. She was treated according to the French protocol LMB01 adapted and received 2 induction COPM treatments (Cyclophosphamide: $500 \mathrm{mg} / \mathrm{m}^{2}$ J2 to J4, Vincristine: 2 $\mathrm{mg} / \mathrm{m}^{2} \mathrm{~J} 1$, Methotrexate: $3 \mathrm{~g} / \mathrm{m}^{2} \mathrm{~J} 1$, Prednisone: $60 \mathrm{mg} / \mathrm{m}^{2}$ D1 to D5 stop in 3 days). The evolution during the induction was marked by moderate tumor regression followed by progression between treatments. A re-induction was performed with DHAP treatments (Dexamethasone: $20 \mathrm{mg} / \mathrm{m}^{2} /$ day J1 to J4 Cisplatin: $100 \mathrm{mg} / \mathrm{m}^{2}$ on D1, Cytosine Arabinoside: $2 \mathrm{~g} / \mathrm{m}^{2} \mathrm{IV}$ twice on D2). The other products received were Metoclopramide and Allopurinol. On day 8 of the second treatment, the patient presented a non-febrile aplasia and received a transfusion of platelet concentrate on Day 8, Day 12, Day 14 and a transfusion of

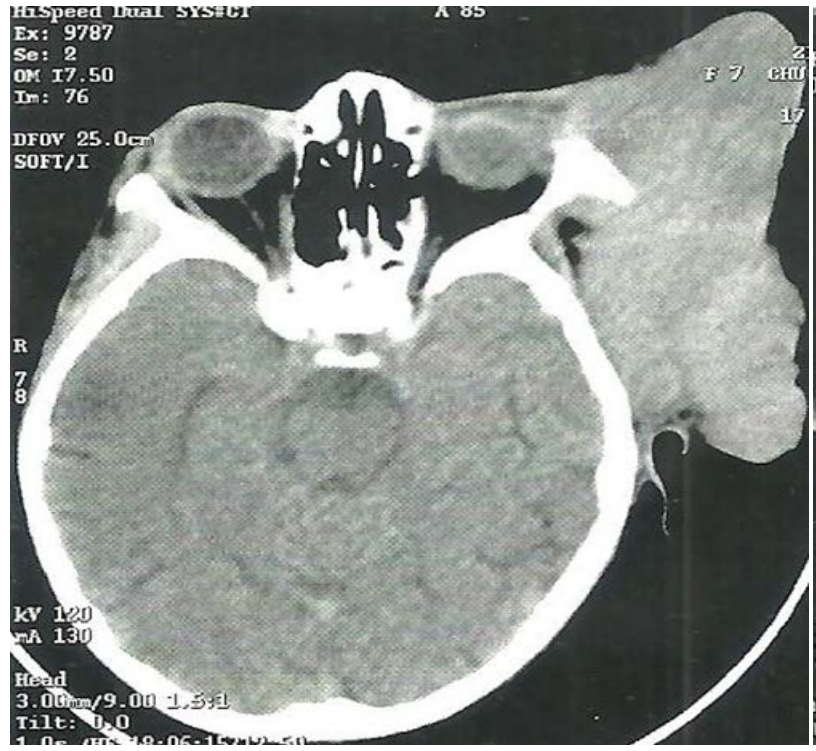

(a)

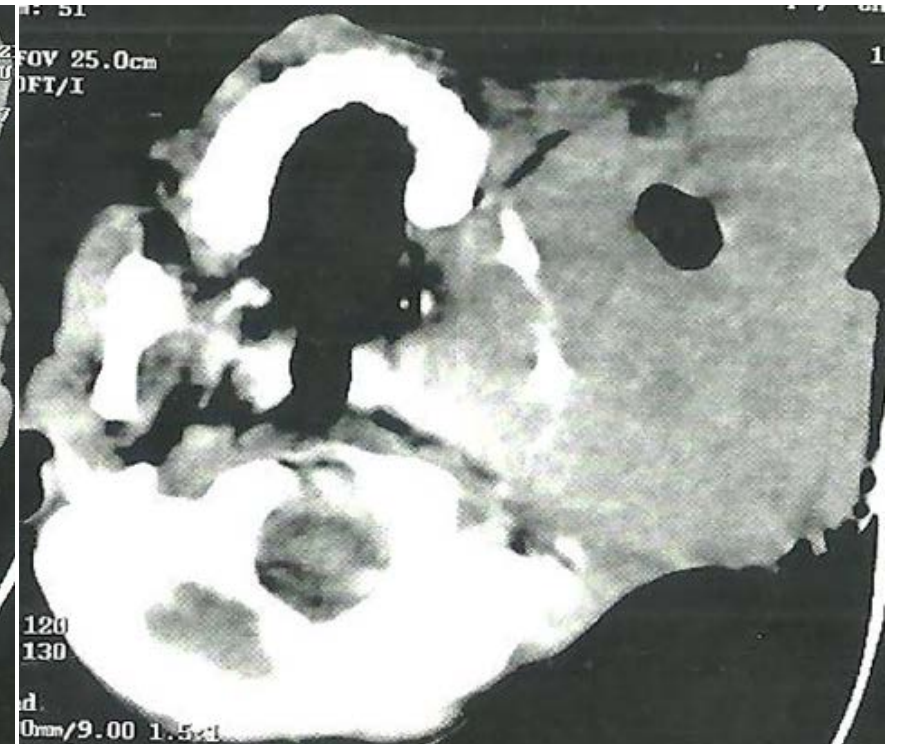

(b)

Figure 1. (a) and (b): Massive facial CT: voluminous tumor of the left hemiface with extension to the orbit, maxillary sinus and lysis of the mandible. 


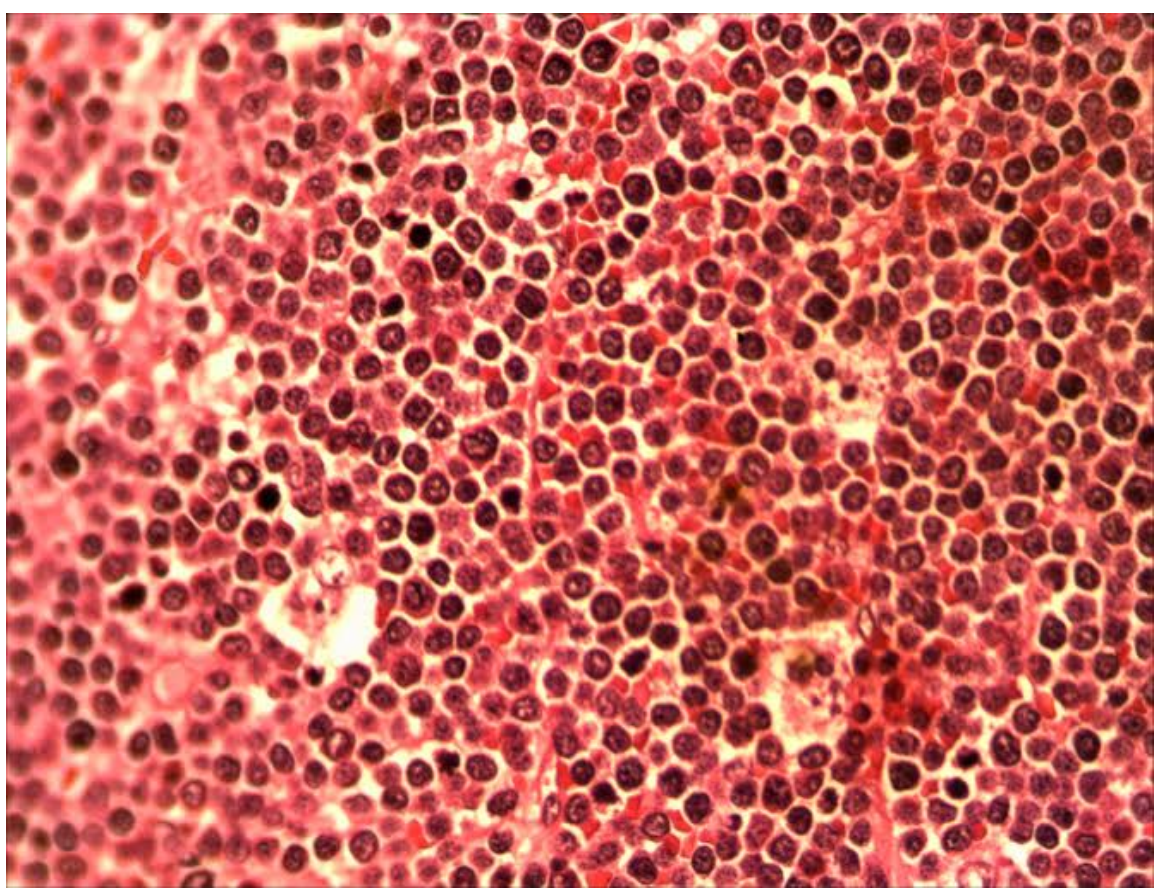

Figure 2. HE $\times$ 400: Monomorphic proliferation of medium-sized lymphoid cells with scanty cytoplasm containing a pale chromatin vesicular nucleus. Presence of macrophages, with tangible body within the cellular layers, giving a starry sky appearance.

red blood cells at Day 12 and Day 14. On Day 19 she presented signs associating tachycardia with gallop noise ( $\mathrm{FC}=124 \mathrm{batt} / \mathrm{min}$ ), diffuse abdominal pain, vomiting and oliguria; the results obtained were as follows: GB: $8500 / \mathrm{mm}^{3}$ (normal: 4 to $10000 / \mathrm{mm}^{3}$ ) HB: $10.0 \mathrm{~g} / \mathrm{l}$ (normal: 12 to $\left.14 \mathrm{~g} / \mathrm{l}\right)\left(\mathrm{Normal}<1700 / \mathrm{mm}^{3}\right)$ Total bilirubin: $1.5 \mathrm{mg} / \mathrm{dl}$ ALAT: $38 \mathrm{IU} / \mathrm{L}$ (normal <40 IU/L) ASAT: $32 \mathrm{IU} / \mathrm{L}$ normal < 30 IU/L), creatinine: 49.56 micromoles/l (normal: 35 - 44 micromol/l). There was a gradual worsening of the clinical picture marked on day 24 with generalized edema and a 7.5\% weight gain, a painful hepatomegaly (hepatic arrow 14 $\mathrm{cm}$ below the costal border), a subicterus. The abdominal ultrasound showed an ascites of medium abundance, a liver measuring $134 \mathrm{~mm}$ in front of the right kidney, homogeneous echostructure and bilateral grade 1 renal pain. Biologically, abnormalities associated with thrombocytopenia of progressive aggravation $\left(118,000 / \mathrm{mm}^{3}\right.$ at $\mathrm{D} 24$ and $63000 / \mathrm{mm}^{3}$ at D26), anemia at $7.6 \mathrm{~g} / \mathrm{l}$, hyper bilirubinemia (total bilirubin $=3.4 \mathrm{mg} / \mathrm{dL}$, normal $<1.2 \mathrm{mg} / \mathrm{dL}$ ), hepatic cytolysis (ALT: 122 IU/l, ASAT: 204 IU/l) at day 24. Parasitic (malaria, bilharziosis) and viral (EBV, CMV, hepatitis B and C and HIV) serology were negative. The diagnosis of hepatic sinusoidal obstruction syndrome was made. The treatment included water restriction, low sodium diet, diuresis (furosemide and spironolactone), and corticosteroid administration. The bilirubin and the transaminases increased (total bilirubin: $5.5 \mathrm{mg} / \mathrm{dL}$, ALAT: $158 \mathrm{IU} / \mathrm{L}$ ASAT: $323 \mathrm{IU} / \mathrm{L}$ ), the renal functions degraded (creatinine: 275,235 micromol/l) and a respiratory distress occurred. The patient died at D33 in a multi-visceral failure chart. 


\section{Discussion}

The hepatic sinusoidal obstruction syndrome is a serious disease that results from alteration of endothelial cells and hepatocellular lesions. It is characterized by clinical and biological signs related to liver damage without other identifiable causes of a liver disease [1]. The pathogenesis of VOD is complex. The histological confirmation represents the gold standard of diagnosis [4]. However, the risk associated with the invasive nature of liver biopsy, the perfect correlation between histology and clinical signs of hepatic dysfunction, validated the clinical diagnosis [4] [5]. Criteria have been established for the diagnosis of this disease. The Seattle Criteria stipulate that the diagnosis of VOD is made in front of at least two of the signs including a jaundice, a painful hepatomegaly or ascites, and/or an unexplained weight gain occurring within 30 days after transplantation. The Baltimore criteria include an increase in bilirubinaemia of at least 2 $\mathrm{mg} / \mathrm{dL}$ associated with two or more of the following signs: hepatomegaly, ascites, or weight gain of at least 5\% within 21 days after transplantation [1] [4] [5]. The SOS is a common complication of hematopoietic stem cell transplantation [1] [2]. Its prevalence during transplantation in children varies from 5 to $60 \%$ with an average of $25 \%$ [5] [6]. This variability depends on the conditioning treatment and the type of transplant, as well as on the diagnostic criteria used. The VOD is more frequent in allografts compared to the autografts $(13 \%-20 \%$ vs 9-10\%) and in packs using total body irradiation, The Busulfan and/or the Cyclophosphamide. The frequency is higher with the Seattle criteria than with those of Baltimore (17.3\% vs 9.6\%) [4] [5] [6] [7]. The main risk factors reported in children in addition to myeloablative conditioning treatments and allogenic grafts are young age, pre-existing liver disease or irradiation, parenteral nutrition [5] [7]. The Hepatic sinusoidal obstruction syndrome has also been described during conventional chemotherapy of nephroblastoma and rhabdomyosarcoma. The prevalence varies from $1.2 \%$ to $8 \%$ for nephroblastoma and from $1.2 \%$ to $5.3 \%$ for rhabdomyosarcoma. The Actinomycin D is the major etiological factor identified in the case of nephroblastoma; The chemotherapy with VAC treatments (Vincristine, Actinomycin D, Cyclophosphamide) and young childhood (less than 36 months) are the main risk factors for rhabdomyosarcoma [8] [9]. This syndrome is also a common complication of the treatment of acute lymphoblastic leukemia using 6-thioguanine [10], whereas only isolated cases have been reported during the induction treatment of leukemia [11] [12]. The SOS has been described in series of children with an autograft of hematopoietic stem cells for malignant lymphomas [13], but it is very rare during conventional lymphoma chemotherapy. We report to our knowledge the second fatal case of VOD during the induction of lymphoma. The first case published by Yamamoto and $\mathrm{Al}$ is that of an overweight 9-year-old child who presented central nervous system lymphoma treated with Vincristine, Cyclophosphamide, Daunorubicin, L-Asparaginase. The causal agent identified was vincristine, the risk factors for death were severity of VOD and the overweight [3]. In our case the drugs re- 
ceived were Cytosine Arabinoside high dose, Cisplatin and dexamethasone. Our case emphasizes the appearance of SOS outside the usual framework described. The anti-cancer drugs may have variable liver toxicity ranging from elevated transaminases to life-threatening hepatic necrosis [14]. The hepatic lesions occurring during cancer treatment may result from the combined action of anticancer agents, antibiotics, antiemetics, analgesics or other drugs. The pre-existing medical problems (hepatitis, other infections, nutritional deficiencies and parenteral nutrition) may influence the response of the host to drug toxicity [15]. The SOS may result from the use of specific anti-cancer combinations [2]. Kotécha et al. described a case in a child with medulloblastoma who received maintenance therapy with vincristine, cisplatin and cyclophosphamide in whom hepatic involvement was attributed to vincristine [16]. Bairey et al. reported a case of VOD that occurred during LAM induction with a combination of Idarubicin, Cytosine Arabinoside, and Etoposide. The reintroduction of Cytosine Arabinoside in consolidation did not produce another episode. The VOD was attributed to the combined effect of the toxicity of all drugs received including antibiotics and antifungals [2]. Kirtley DW et al. described a fatal case in a patient with relapsing LAM, who received standard doses of cytosine arabinoside, vincristine, 6-thioguanine, daunorubicin, and developed an SOS under Cytosine Arabinoside administered in high doses; the other products concomitantly received were metoclopramide, allopurinol, dexamethasone and diazepam. The hepatotoxicity of the treatment was related to high doses of Cytosine Arabinoside [17]. The VOD in our case was attributed to the combined effect of high doses of Cytosine Arabinoside and other drugs received. Several therapeutic strategies are proposed in addition to supportive care: the high-dose methylprednisolone, the antithrombin III-associated heparin, the $\mathrm{N}$ acetylcysteine, the Defibrotide [18]. The Defibrotide is an oligonucleotide with a local anti-thrombotic affect, anti-ischemic, anti-inflammatory activity, with no significant side effects. This treatment has been shown to be effective in the management of VOD during transplantation [1] [19]. The severity of VOD is a key prognostic factor; the published series report mortality rates ranging from 50 to $85 \%$ in severe forms. Three increasing levels of severity are described: the mild form (resolution of symptoms and decrease in bilirubin $<34.2 \mu \mathrm{mol} / \mathrm{l}$ ( $<2 \mathrm{mg} / \mathrm{dl}$ ) with or without specific treatment), moderate form (presence of clinical signs of progressive disease in ascites or pleurisy but without signs of multivisceral failure) and severe form (multivisceral failure, oxygen requirement, mechanical ventilation and/or renal failure and/or encephalopathy) [16] [19].

\section{Conclusion}

We described the observation of a child with Burkitt's lymphoma who developed a fatal SOS during induction chemotherapy. This observation shows that the diagnosis of VOD should not be excluded in the absence of the risk factors usually described. 


\section{Conflict of Interest}

The authors declares that there is no conflict of interest regarding the publication of this paper.

\section{Consent}

NB: informed consent has been obtained from the patient's parent to report the case.

\section{References}

[1] Richardson, G.P., Ho, T.V., Giralt, S., et al. (2012) Safety and Efficacy of Defibrotide for Treatment of Severe Hepatic Veno-Occlusive Disease. Therapeutic Advances in Hematology, 3, 253-265. https://doi.org/10.1177/2040620712441943

[2] Bairey, O., Kirgner, I., Yakobi, M., et al. (2002) Clinical Severe Hepatic Venooclusive Disease during Induction Treatment of Acute Monoblastic Leukemia Managed with Defibrotide. American Journal of Hematology, 69, 281-284.

https://doi.org/10.1002/ajh.10072

[3] Yamamoto, S., Akiyama, K., Oyama, N., et al. (2012) Fatal Hepatic Sinusoidal Obstruction Syndrome in a Child with Primary CNS Lymphoma during Induction Therapy. International Journal of Hematology, 96, 284-286.

https://doi.org/10.1007/s12185-012-1128-4

[4] Coppell, A.J., Richardson, G.P., Soiffer, R., et al. (2010) Hepatic Veno-Occlusive Disease following Stem Cell Transplantation: Incidence, Clinical Course, and Outcome. Biology of Blood and Marrow Transplantation, 16, 157-168. https://doi.org/10.1016/j.bbmt.2009.08.024

[5] Corbacioglu, S., Kernan, N., Lehmann, L., et al. (2012) Defibrotide for the Treatment of Hepatic Veno-Occlusive Disease in Children after Hematopoietic Stem Cell Transplantation. Expert Review of Hematology, 5, 291-302. https://doi.org/10.1586/ehm.12.18

[6] McDonald, G.B., Sharma, P., Matthews, D.E., et al. (1984) Venocclusive Disease of the Liver after Bone Marrow Transplantation: Diagnosis, Incidence, and Predisposing Factors. Hepatology, 4, 116-122. https://doi.org/10.1002/hep.1840040121

[7] Cesaro, E., Pillon, S., Talenti, M., et al. (2005) A Prospective Survey on Incidence, Risk Factors and Therapy of Hepatic Veno-Occlusive Disease in Children after Hematopoietic Stem Cell Transplantation. Haematologica, 90, 1396-1404.

[8] D’Antiga, L., Baker, A., Pritchard, J., et al. (2001) Veno-Occlusive Disease with Multi-Organ Involvement Following Actinomycin-D. European Journal of Cancer, 37, 1141-1148. https://doi.org/10.1016/S0959-8049(01)00097-1

[9] Arndt, C., Hawkins, D., Anderson, J.R., et al. (2004) Age is a Risk Factor for Chemotherapy-Induced Hepatopathy with Vincristine, Dactinomycin, and Cyclophosphamide. Journal of Clinical Oncology, 22, 1894-1901. https://doi.org/10.1200/JCO.2004.08.075

[10] Stork, C.L., Matloub, Y., Broxson, E., et al. (2010) Oral 6-mercaptopurine versus oral 6-thioguanine and Veno-Occlusive Disease in Children with Standard-Risk Acute Lymphoblastic Leukemia: Report of the Children's Oncology Group CCG-1952 Clinical Trial. Blood, 115, 2740-2748. https://doi.org/10.1182/blood-2009-07-230656

[11] Kraemer, D.M., Waschke, J., Kunzmann, V., et al. (2003) Veno-Occlusive Disease in 
a Male Patient with Marfan Syndrome and Common Acute Lymphoblastic Leukemia during Induction Therapy. Annals of Hematology, 82, 444-447. https://doi.org/10.1007/s00277-003-0669-2

[12] Papadopoulos, A., Ntaios, G., Kaiafa, G., et al. (2008) Veno-Occlusive Disease of the Liver during Induction Therapy for Acute Lymphoblastic Leukemia. International Journal of Hematology, 88, 441-442. https://doi.org/10.1007/s12185-008-0172-6

[13] Andion, M., Molina, B., Gonzalez-Vicent, M., et al. (2011) High-Dose Busulfan and Cyclophosphamide as a Conditioning Regimen for Autologous Peripheral Blood Stem Cell Transplantation in Childhood Non-Hodgkin Lymphoma Patients: A Long-Term Follow-Up Study. Journal of Pediatric Hematology/Oncology, 33, e89-e91. https://doi.org/10.1097/MPH.0b013e3181fd6c79

[14] King, P.D. and Perry, M.C. (2001) Hepatotoxicity of Chemotherapy. Oncologist, 6, 162-176. https://doi.org/10.1634/theoncologist.6-2-162

[15] Benichou, C. (1990) Criteria of Drug-Induced Liver Disorders: Report of an International Consensus Meeting. Journal of Hepatology, 11, 272-276. https://doi.org/10.1016/0168-8278(90)90124-A

[16] Kotecha, R.S., Buckland, A., Phillips, M.B., et al. (2014) Hepatic Sinusoidal Obstruction Syndrome during Chemotherapy for Childhood Medulloblastoma: Report of a Case and Review of the Literature. Journal of Pediatric Hematologyl Oncology, 36, 76-80. https://doi.org/10.1097/MPH.0b013e3182a8f352

[17] Kirtley, D.W., Voltaw, M.L. and Thomas, E. (1990) Jaundice and Hepatorenal Syndrome Associated with Cytosine Arabinoside. Journal of the National Medical Association, 82, 217-218.

[18] Lee, C.W.A. and Goh, Y.T.P. (2011) Dactinomycin-Induced Hepatic Sinusoidal Obstruction Syndrome Responding to Treatment with N-Acetylcysteine. Journal of Cancer, 2, 527-531. https://doi.org/10.7150/jca.2.527

[19] Cefalo, M.G., Maurizi, P., Arlotta, A., et al. (2010) Hepatic Veno-Occlusive Disease: A Chemotherapy-Related Toxicity in Children with Malignancies. Paediatric Drugs, 12, 277-284. https://doi.org/10.2165/11531840-000000000-00000 